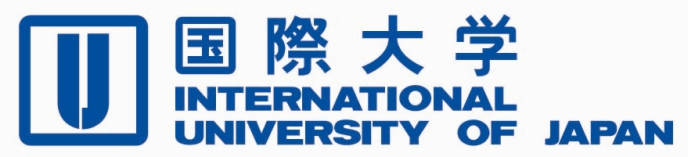

Economics \& Management Series

EMS-2012-17

\title{
Networking Partner Selection and Its Impact on the Perceived Success of Collaboration
}

\author{
Sangyub Ryu \\ International University of Japan
}

September 2012

IUJ Research Institute

International University of Japan

These working papers are preliminary research documents published by the IUJ research institute. To facilitate prompt distribution, they have not been formally reviewed and edited. They are circulated in order to stimulate discussion and critical comment and may be revised. The views and interpretations expressed in these papers are those of the author(s). It is expected that the working papers will be published in some other form. 
Networking Partner Selection and Its Impact on the Perceived Success of Collaboration

\section{Sangyub Ryu}

Public Management and Policy Analysis Program

Graduate School of International Relations

The International University of Japan

777 Kokusai-cho, Minami Uonuma-shi

Niigata, 949-7277, Japan

Email: sangyubr@iuj.ac.jp 
Networking Partner Selection and Its Impact on the Perceived Success of Collaboration

\section{Abstract}

Scholars have emphasized networks as a new agenda or a necessary tool for solving public problems and research on networks have been actively conducted. However, little attention has been given to how networking partners are selected and activated. This question is critical when a networking partner is voluntarily chosen. To fill this gap in knowledge, this study proposes four possible scenarios for the selection of networking partners based on the intention to network with a potential partner and the activation of networking with that partner. Results show that the scenario of not-intended-but-nonetheless-activated networking brings the highest increase in perceived success of collaboration while the scenario of intended-and-activated networking results in the second highest among the four scenarios. However, it was also found that the scenario of not-intended-but-nonetheless-activated networking is less likely in the real world where public managers are asked to strategically find beneficial partner candidates and to achieve the activation of networking with those candidates. This study expects to promote understanding of the process of networking partner selection. 


\section{Introduction}

As current public problems become more complex, or "wicked," public manages reached their limit to resolve such problems for themselves. As a result, public managers have sought solutions from the outside by networking with their environmental actors. In so doing, public managers could obtain scarce but necessary resources from their networking partners. At last, networking becomes a pivotal agenda or a necessary tool for solving public problems, and research on networking has been actively conducted in the field of public administration for the last two decades (Frederickson 1999; O’Toole 1997). During this period, significant efforts to understand networking were made although many questions remain unanswered (Provan, Fish, and Sydow 2007). One of these questions is how one selects networking partners and what process of networking partner selection is taken (Graddy and Chen, 209; Jarimo, Salkari, and Bollhalter, 2006; Robinson and Bies 2010). Some scholars have treated issues about networking partner selection seriously. For instance, Scharpf (1978, p.364) saw networking partner selection as "an essential prerequisite for successful interorganizational policy formation and policy implementation.” Agranoff and McGuire (2001) also stressed networking with the right partners as a critical element of activating networks. Despite a consensus on the importance of networking partner selection, few empirical studies have analyzed the process of networking partner selection. To fill this gap, this study investigates the association between networking partner selection and changes in the perceived success of collaboration as its outcome. First, this study conceptually distinguishes networking and collaboration, followed by previous literature on the networking partner selection. Then, four scenarios of networking partner selection are proposed with hypotheses of how each scenario impacts changes in the perceived success of 
collaboration. Using emergency management data in Texas, statistical findings to test hypotheses will be reported. At the end, conclusion and discussion for future research will be addressed.

\section{Conceptual Distinction between Networking and Collaboration}

Current studies on collaborative public management have used mixed terms such as collaboration, networking, or cooperation without clear definition. However, some scholars argue that they are conceptually distinctive. For instance, Selden, Sowa, and Sandfort (2006) distinguish concepts of cooperation, coordination, collaboration, and service integration by positioning them in the continuum of collaborative service arrangement in a row (cooperationcoordination-collaboration-service integration) based on the intensity of the relationship. They argue that cooperation is the least intense, informal relationship while service integration is the most intense, service-oriented relationship. Coordination and collaboration are located between these two poles (Selden, Sowa, and Sandfort, 2006). However, they admit that these concepts are frequently used interchangeably. Agranoff and McGuire (2003) give more clear definition about collaboration. They define collaboration as "a purposive relationship designed to solve a problem by creating or discovering a solution within a given set of constraints" (p.4). They contend that collaboration is a different concept from cooperation in that both refer to working jointly while cooperation seeks to be helpful as opposed to hostile.

Networking, on the other hand, refers to individual's behaviors to activate, frame, mobilize, and synthesize among participants (Agranoff and McGuire 2001) in the networked setting in which networks are "structures of interdependence involving multiple organizations or parts thereof, where one unit is not merely the formal subordinate of the others in some large hierarchical arrangement." (O’Toole, 1997. p.45). Networking aims at problem-solving just as collaboration does. However, networking and collaboration are distinctive concepts. According 
to Robinson and Gettis (2007), networking includes a temporal dimension (frequency in time) and an intensity dimension (interaction in depth) such that active networking is more intensive and frequent interactions than collaboration. Because networking captures interactions with higher thresholds, how a networking partner is selected may influence collaborative activities and their success.

\section{Antecedent of Networking Partner Selection}

Aside the political/practical call for networking (Hall and O'Toole, 2000), resource-dependency well explains behaviors of organizational networking (Fleishman, 2009; Oliver and Ebers, 1998). The basic logic is that organizations do not have all the necessary resources to achieve their goals, and they network with their external actors which hold those resources (Van de Ven, Emmett, and Koening 1975 cited in Fleishman, 2009). Despite the importance of networking for organizational survival, more networking partners are not always better. According to Hicklin, O'Toole and Meier (2008), beyond a certain point, additional networking partners result in more costs than benefits, thus negatively affecting organizational performance. Thus, one needs to take a strategic approach to networking partner selection with considering expected benefits from the partnership and its associated risks and costs (Graddy and Chen 2009; Robinson 2011). In this sense, it is ideal for decision makers to take the following steps when assessing potential partners: 1) identifying relevant costs and benefits generated from holding an additional networking partner; 2) measuring costs and benefits; 3) comparing costs and benefits; and 4) making decisions (Nas, 1996).

When a networking partner is selected, the selector faces the next, perhaps more complex situation because one's selection does not guarantee the actual activation of networking. The activation of a new networking relationship is a product of mutual agreement between the 
selector and the selected partner. When selected, the selected partner also go through the similar cost-benefit assessment in order to determine whether the selected accepts the offer and activate the networking relationship. If the selected determines that networking results in more costs than benefits, the networking would not be activated. As such, a potential partner's motivation or desire to activate networking is another important factor that has to be considered (Jarimo et al., 2006).

Empirical findings support the complex networking partner selection processes. For instance Fleishman (2009) interviewed and surveyed participants in four estuary partnerships. She found that access to useful information motivates participants most to take part in estuary partnership. That is, one is mostly motivated to network with others if networking brings some benefits, such as access to useful information. However, considering reciprocal resource sharing relationship between networking partners, her finding also revealed that when activating networking, one has to consider what he will get from potential partners but also what he can provide to them.

Graddy and Chen (2009) make a similar argument about partner selection. They view networking as inherently risky relationships because interdependent relationships can be broken by a partner's behavior. Thus, decision makers have to conduct an assessment to select the most satisfactory networking partner. They stress the assessment of the trade-off between the benefits of networking and the costs of a failure to activate networking. This suggests that one has to strategically select one's networking partners by assessing both the positive and negative outcomes that potential partners will bring (Graddy and Chen 2009). They also assert that the exchange of resources that one does and does not possess and the organizational legitimacy that returns associational advantages are two broad categories that one expects from the networking. 
When comparing potential networking partners who will return similar benefits, one maximizes one's benefits by seeking those who generate lower costs among networking partner candidates (Graddy and Chen 2009). In order to do so, they argue that it is essential to have information about a potential partner.

In summary, networking with an appropriate partner should result in more benefits than costs and networking with an inappropriate or unnecessary partner can lead to negative outcomes. Thus, it is important to identify the most beneficial networking partner. At the same time, decision makers are required to recognize how the networking partner can benefit. Only a careful assessment of the potential exchange will lead to the successful activation and maintenance of a networking relationship. Therefore, decision makers should take a strategic approach to networking partner selection.

\section{Scenarios of Networking Partner Selection and Assumptions}

Literature reviewed so far suggests that networking partner selection is a complex but important management strategy. Despite the consensus on the importance of partner selection, few have developed a framework of how a networking partner is selected. To fill this gap, this study suggests four scenarios of networking partner selection. There is limited research on the process of networking partner selection. One useful remark may be found from Robinson's (2011) research. He finds three major motivators for partner choice. First, he argues that new partnership is activated when the expected utility of the partnership exceeds the expected costs of the collaboration. Second, a new partnership is easily established when one attempts to network with a partner with similar characteristics (Robinson 2011). Third, contrary to the second argument, Robinson points that one expects new partnership with heterogeneous others to attain what the one does not have. 
In addition to Robinson's research on partner choice, this study takes a new approach to partner selection. Because this study is one of the first attempts, this study mainly relies on a few assumptions in order to draw scenarios. Some assumptions may be strong, and this study expects future research to test or modify any of assumptions developed here for better frameworks of networking partner selection.

In order to activate networking between two actors, both actors go through a decision making process. In this process, they evaluate expected benefits and costs that may result from the networking. They would activate networking only when both of them arrive at the conclusion that the benefits expected from networking are greater than the costs. Thus, to understand the activation of a new networking relationship, both sides' decision-making has to be taken into account.

This study will narrow down the scope of decision-making to the focal actor's (an ego ${ }^{1}$ ) perspective. Even if networking requires mutual agreement, it is reasonable to assess a decisionmaking process in terms of an ego's perspective because, in reality, one with bounded rationality may need to make decisions by oneself without knowing a potential partner's preferences or decisions.

\section{A. Scenarios}

Scenarios described in Table 1 are developed based on two categories- intention to network and activation of the networking. The scenario sets a situation in which an ego determines to network with a certain potential partner.

[Table 1 about here]

Scenario I. The ego determines that it could possibly benefit from the networking with a certain candidate. At the same time, it assesses itself as an attractive networking partner for that

\footnotetext{
${ }^{1}$ In this study, an ego refers to a focal organization.
} 
candidate and attempts to activate networking with that candidate. If the ego's self-evaluation has been correct and the candidate finds some expected benefits from networking with the ego, collaboration is activated.

Scenario II. After self-evaluation, the ego is interested in networking with a certain candidate but perceives itself as insufficiently attractive for that candidate so it does not take actions to attempt to activate networking with that candidate. However, the candidate finds some expected benefits from the networking with the ego and attempts to activate networking by contacting the ego. As a result, networking is activated.

Scenario III. The ego perceives itself sufficiently attractive for a certain candidate after selfevaluation and attempts to activate networking with that candidate. However, the candidate does not find benefits from the networking with the ego. The activation of networking should be based on mutual agreement but because the candidate does not agree, the ego fails to activate networking.

Scenario IV. In this scenario, like Scenario III, no networking is activated. However, the reason is different from that found in Scenario III. An ego does not perceive itself sufficiently attractive for a certain candidate. At the same time, that candidate does not find the incentive to networking with the ego either. As a result, no exchanges occur.

To clearly understand each conceptual scenario and develop hypotheses, this study sets five assumptions introduced in the following section.

\section{B. Assumptions}

Assumption 1: A networking partner in each scenario is expected to bring benefits to the ego. 
Whether or not networking with a certain partner will bring benefits to the ego is not definite. To make sure, the ego has to make an assessment of expected costs and benefits. The ego may find that networking with some candidates will bring benefits but networking with some others will not. In other words, not all potential networking is always beneficial. However, this study assumes that the ego has already conducted an assessment to screen those potential partners who will not return benefits. Thus, the ego has to decide whether it will attempt to activate networking with a certain partner among those partners who have potential benefits for the ego.

Assumption 2: The ego does not have full information about whether a networking candidate finds any benefits from the networking with the ego.

This scenario is from an ego's perspective. The ego does not know how potential candidates evaluate the ego. The ego may think that it can return something to the candidate through networking, but the candidate may or may not agree. The ego may also think it cannot return what the candidate wants from networking, but the candidate may have different ideas. This study assumes that the ego typically makes a decision of whether or not it will attempt to activate networking with a candidate without knowing the intention of that candidate.

Assumption 3: The outcomes of networking with a certain candidate are the same regardless of how the networking is activated.

Networking can be activated either through the initiative of the ego or the candidate (Scenario I or Scenario II). In either case, this study assumes that the outcomes of networking are the same. 
Assumption 4: Each scenario will generate costs involving a combination of the following three types: costs for 1) self-evaluation, 2) the attempt to activate collaboration, and 3) the process of activation.

Under an uncertain situation in which the ego does not know whether or not the candidate will find benefits, the ego should conduct an assessment. From the results of an assessment, the ego may or may not find itself sufficiently attractive to the candidate to accept the offer to activate networking. This assessment will generate costs. If the ego finds itself sufficiently attractive to the networking candidate, it will attempt to activate networking by, for instance, contacting and persuading the candidate. Regardless of the results of the attempt, this process will generate costs. If the ego and the networking candidate mutually agree on the activation of networking, they have to pay costs together to activate networking. This process may include setting goals, priorities or strategies.

Assumption 5: Costs for a particular action are the same for all scenarios.

This study assumes that a particular action will generate the same costs regardless of scenarios. For instance, if the ego conducts self-evaluation, the self-evaluation will generate the same costs in any scenarios.

\section{Networking Partner Selection and the Success of Collaboration}

The outcomes of networking partner selection can be various; they can be client goal achievement, improved interogranizational relationships, or organizational development (Graddy and Chen, 2009). This study gives a special attention to changes in the perceived success of collaboration as a result of networking partner selection. Studies on collaboration have actively sough detrimental factors for the success of collaboration. Oliver and Ebers (1998) conducted an extensive literature review and found that among those of 158 articles that they reviewed, 36 
articles $(22.8 \%)$ investigated collaboration success as an outcome variable. It was the second to the highest theme. ${ }^{2}$ Although collaboration success is a broad concept, it overarches subdimensions of collaboration outcomes. Thus, the success of collaboration is a core question of collaboration studies, and the available data allows this study to examine changes in the perceived success of collaboration as a proxy of collaboration success.

This study hypothesizes that different scenarios of partner selection result in different changes in the perceived success of collaboration. To draw hypotheses, this study compares costs and benefits of each scenario shown in Table 2 .

\section{[Table 2 about here]}

Table 2 shows costs and benefits that are expected to an ego in each scenario based on Assumption 3 and Assumption 4. Based on Assumption 1, this study expects that the outcome of networking will be positive. Thus, the outcomes of both Scenario I and Scenario II will be positive increases in the perceived success of collaboration. However, the costs generated and paid are different between the two. The ego both in Scenario I and in Scenario II pays costs for self-evaluation and the process of activation of networking. By Assumption 5, total costs for these activities in Scenario I and Scenario II are same. However, the ego in Scenario I should pay costs for the attempt to activate networking; thus, the ego in Scenario I pays more costs than the ego in Scenario II. Even if Scenario I and Scenario II have the same effects of networking (by Assumption 1), the ego in Scenario I pays more costs than the ego in Scenario II; thus, the ego in Scenario II achieves more returns from networking with a networking candidate than the ego in Scenario I.

\footnotetext{
${ }^{2}$ The most investigated outcome variable was power and control $(n=49,31 \%)$
} 
Hypothesis 1: Changes in the perceived success of collaboration with a networking candidate are most positive if networking with that candidate is not activated by the ego (Scenario II).

Hypothesis 2: Changes in the perceived success of collaboration with a networking candidate are second most positive, if the ego intends to activate networking with that candidate, and that networking later does occur (Scenario I).

Meanwhile, there are no networking benefits in Scenario III and Scenario IV but a negative outcome may be generated in these scenarios due to costs. In both Scenario III and Scenario IV, the ego pays for self-evaluation. The ego pays more in Scenario III than in Scenario IV via the cost in the attempt to activate networking with a networking partner. As a result, the negative impact in Scenario III may be worse than that in Scenario IV. Thus, this study hypothesizes as follows:

Hypothesis 3: Changes in the perceived success of collaboration with a networking candidate are lowest if the ego intends to activate networking with that candidate, which does not then occur (Scenario III).

Hypothesis 4: Changes in the perceived success of collaboration with a networking candidate are second lowest, if networking, which the ego does not intend to activate, does not occur (Scenario IV).

Tests of the hypotheses above allow this study to examine which scenario brings the highest marginal effects and which scenario brings the lowest marginal effects. For better understanding of decision-making in partner selection, it is worthwhile to consider the expected values of each scenario because benefits and potential chances of the occurrence 
of each scenario may suggest different strategies from the test of hypotheses above. For instance, as hypothesized, even if benefits from Scenario II are higher than benefits from Scenario I, the expected value of Scenario II could be lower than that of Scenario I if the possibility that Scenario II occurs is substantially lower than the possibility that Scenario I occurs. If so, the best strategy for an ego will be to actively attempt to activate networking with beneficial candidates (Scenario I). In order to examine strategies with given scenarios, this study will compare the expected value of each scenario based on each scenario's marginal effects and its chance of occurrence in the sample.

\section{Data and Sample}

This study utilizes two post-hurricane surveys. The first post-hurricane survey is "Emergency Preparedness and the Impact of Hurricanes Katrina and Rita on Texas School Districts." This survey was coordinated by researchers at Texas A\&M University and the University of Texas at Dallas. Data collection from superintendents of Texas school districts was conducted right after Hurricanes Katrina and Rita, ${ }^{3}$ and the collection was finished by early 2006.720 of the superintendents responded to the first post-hurricane survey (response rate: 58 percent). The second post-hurricane survey, "Emergency Preparedness in Texas' School Districts in 2007," is also used for the analysis. The second post-hurricane survey was conducted in early 2007 in Texas school districts and recorded 48 percent of response rate (595 superintendents). Both surveys asked superintendents about their behaviors and strategies for emergency management. The dependent variable and the independent variables of interests are derived from both surveys.

In addition, some control variables are drawn either from the first post-hurricane survey or from the 2005-06 Academic Excellence Indicator System on the website of the Texas

\footnotetext{
${ }^{3}$ The survey was initiated in November, 2005.
} 
Education Agency. ${ }^{4}$ The main research question is how each of the four scenarios of managers' networking partner selection influences the success of collaboration. Tracking intention to network with a potential partner at Time $\mathrm{T}$ and activation of that partner at Time $\mathrm{T}+1$ require the same respondence over years, which ensures internal validity. Thus, this study samples only those superintendents who responded to both surveys. Any superintendents who were newly employed or recently left between Time 1 (2005-06) and Time 2 (2007) are dropped in the analysis. $^{5}$

The surveys asked about superintendents' collaborative behaviors in regards to emergency preparedness. The main target external organizations were 1) police, fire department, and first responders, 2) government relief and welfare organizations, 3) nonprofit and relief organizations, 4) local/community/religious organizations, 5) other school districts, and 6) business organizations. This study initially examined superintendents' perception on the success of collaboration with each of the organizations above. However, it was found that the model investigating the success of collaboration with other school districts is the only one that statistically satisfies model-fit. ${ }^{6}$ It is not certain at this point what caused such results. More discussion will be noted in the conclusion/discussion section. In this study, only results of the model estimating changes in the perceived success of collaboration with other school districts will be reported.

Among those superintendents who responded to both surveys, some already had networking with other school districts while the others had not. With the given data, it cannot be determined if superintendents annually reassess the value of networking with other school

\footnotetext{
${ }^{4}$ 2005-06 Academic Excellence Indicator System Available at http://ritter.tea.state.tx.us/perfreport/aeis/2006/index.html, accessed on October 29, 2011.

${ }_{5}^{5} 3$ superintendents are dropped.

${ }^{6}$ The author experimented with different model specifications for the other 5 models; however, models with statistically significant goodness-of-fit were not found with the given data.
} 
districts with regard to emergency management. If superintendents do not reassess the value of existing networking, any costs generated for activation could be zero. Even if the given data do not specify such annual reassessment for exiting networking, 93.6\% of the districts which responded to the survey went through a regular review of their emergency plan, and among them, about $82 \%$ of school districts conducted annual or bi-annual reviews, which might include reassessment of their emergency networking. Therefore, it is plausible that networking with existing partners still generates activation costs. However, again, the data do not specify whether superintendents reassessed their networking, and in order to see if there are differences in findings, this study partitions the whole sample into two sub-samples: one sub-sample of superintendents who have had networking with other school districts at Time $1(n=120)$ and the other sub-sample of superintendents who have not had networking with other school districts at Time $1(\mathrm{n}=60)$. The present study will analyze both partitioned sub-samples as well as the whole sample.

\section{Variables}

\section{A. Measuring changes in the perceived success of collaboration}

The dependent variable is measured by using superintendents' perception of the success of collaboration with other school districts in 2005-06 (Time 1) and in 2007 (Time 2). Both the first post-hurricane survey collected at Time 1 and the second post-hurricane survey collected at Time 2 asked superintendents to rate the degree of success that their district experienced in collaboration with other school districts. Each question is scored ranging from 1 (poor) to 4 (excellent). To measure changes in the success of collaboration, this study subtracts rates on the success of collaboration at Time 1 from rates on the success of collaboration at Time 2 . The distribution of the change of perceived collaboration success is shown in Table 3 . About 33 
percent of the sample responded that their level of collaboration success decreased over the period. About 48 percent of respondents perceived the same level of collaboration success between the two periods. About 19 percent of respondents rated a higher level of collaboration success as compared to the previous years.

[Table 3 about here]

Table 3 shows that there are only a few observations that indicate the level of collaboration success changed more than one level over the time period. Seven of them reported that the success of their collaboration decreased two or three levels. Likewise, another six of them perceived that the success of their collaboration increased two levels. Ordered probit regression will be employed to explain the reported changes. Extremely small observations in any of the categories make the analysis difficult. ${ }^{7}$ Thus, it may be reasonable to combine all decreased levels of collaboration success into one category, "decrease" (=1) and all increased levels of collaboration success into the other category, "increased" (=3). In short, the dependent variable is transformed into three categories: "decrease" $(=1)$ if the level of collaboration success decreased over years; "remain same" $(=2)$ if the level of collaboration success remains same; and "increase" (=3) if the level of collaboration success increased. The distribution of the transformed dependent variable is presented in Table 4.

[Table 4 about here]

Measurement relying on one's perception raises issues. Some criticize perceived performance measures because such measures may raise validity and reliability issues due to self-assessment bias (Andrews, Boyne, and Walker 2006; Meier and O'Toole 2010). For instance, Andrews et al. (2006) measure four performance indicators (effectiveness, quality,

\footnotetext{
${ }^{7}$ Introduction to STATA. UCLA: Academic Technology Services, Statistical Consulting Group. from http://www.ats.ucla.edu/stat/stata/dae/ologit.htm (accessed August 12, 2011).
} 
quantity, and equity) using subjective survey items and objective data bases. They compare each subjective indicator with its corresponding objective indicator and find low and insignificant correlation between them. Meier and O'Toole (2010) review previous literature on this subject and they also find no close correlation between subjective and objective performance in the Texas education context. Although they admit that citizens' perception of organizational performance is meaningful as feedback, managerial self-assessment on organizational performance is likely to be biased. Therefore, this study cannot rule out the possibility that the perceptual measure of the success of collaboration could be biased.

However, Andrews et al. (2006) contend that even objective measures of performance raise problems related to accuracy. Organizational performance is a very complex concept and, as Andrews et al. (2006, p. 30) suggest, "no truly objective measures of public service performance exist." Furthermore, Brewer (2006, p. 36) contends that "organizational performance is a socially-constructed concept and all measures of performance are subjective" and argues that it is more likely in the public sector in which "competing views of reality exist and many important disputes are settled by election or mutual accommodation rather than by more objective or rational means." Thus, managers' perception of collaboration success may be an important index.

Collaboration in this study aims to prepare for an emergency. After disastrous hurricanes in 2005, Texas did not experience such a serious emergency to test the performance of emergency-related collaboration. Thus, there is no archival way of measuring objective success of collaboration in preparation for emergencies. Under this situation, measuring changes in the perceived success of collaboration is inherently judgmental. This study uses a perceptual 
measure of collaboration success by admitting both the limitation of and the potential for the subjective measure.

\section{B. Measuring networking partner selection scenarios}

Various approaches are available to measure networking, but the existing measures fail to capture the core of the networking relationship (Robinson and Gettis 2007). As stated earlier, Robinson and Gettis (2007) contend that networking has a temporal dimension (frequency in time) and an intensity dimension (interaction in depth), and some of the current measures of networking in previous literature such as resource sharing may not be necessarily called networking since they fail to capture either of these dimensions.

Taking the temporal dimension and the intensity dimension into account, this study measures networking based on regular contact and regular meeting, which satisfy the temporal dimension and represent intensive networking between participants because participants who could have lots of obligations should show high motivation and commitment in order to activate and maintain regular contact and meetings (Robinson and Gettis 2007).

Given the measures of networking, variables for each networking partner selection scenario are derived using two dichotomous variables - the intention measure and the activation measure. The intention measure is derived from the first post-hurricane survey. The survey asked if superintendents intended on sustaining regular contact with other school districts for the purposes of emergency preparation. The intention measure has a value of one if superintendents intended on sustaining regular contact with other school districts at Time 1; otherwise, it is coded as zero. The activation measure is derived from the second post-hurricane survey. The survey asked superintendents if they held regular meetings with other school districts. If they held regular meetings with other school districts at Time 2 , the activation measure has a value of one; 
otherwise, it has a value of zero. By matching answers from the two dichotomous measures, the following measures are created: intended-and-activated networking (Scenario I; yes to the intention measure and yes to the activation measure), not-intended-but-nonetheless-activated networking (Scenario II; no to the intention measure and yes to the activation measure), intended-but-not-activated networking (Scenario III; yes to the intention measure and no to the activation measure), and not-intended-and-not-activated networking (Scenario IV; no to the intention measure and no to the activation measure). The number of observations falling in each category is presented in Table 5.

[Table 5 about here]

\section{Control variables}

Since the dependent variable is changes in the perceived success of collaboration in emergency management, this study controls for the experience of emergency. Experiencing an emergency during the period when the survey was conducted (between Time 1 and Time 2) may influence managers' perceived success of collaboration in one way or another. To measure recent emergency experience, the second post-hurricane survey asked as follows:

Has your district faced an emergency that called for the activation of your district disaster/emergency plan in:

__ past 6 months past year past two years Not in the past 2 years

The variable is categorical ranging from 1 to 4 where 1 denotes no emergency in the past 2 years and 4 refers to emergency occurred in past 6 months. The mean of this variable is 1.93 with a standard deviation of 1.10 .

Another set of control variables is resources that may be of help for superintendents in collaborating with other school districts. Resources in this model include the percentage of 
central administrative staff and a district's total expenditure aside from that used for central administration. Central administrators support superintendents by assisting with their districts' managerial issues other than school-level day-to-day operations (Meier, O'Toole and Hicklin 2010). Thus, more central administrators may help enhance the success of collaboration in emergency management that managers perceive. In addition, districts' total expenditure except the expenditure on central administration is controlled. The collaboration examined in this study is voluntary. Given a fixed budget, a district may give up some amount of expenditure in some particular areas in order to maintain and enhance collaboration. The current data from the TEA website do not clearly identify expenditures devoted for collaboration. Instead, this study controls for total expenditure. Although the exact amount of expenditure spent on collaboration is not known, districts with more total expenditure may have more chances to spend more money on voluntary collaboration in regard to emergency management. The percentage of central administration and the expenditure in central administration are highly correlated. ${ }^{8}$ Therefore, the total expenditure in this model excludes expenditures for central administration. ${ }^{9}$

This study also controls for a superintendent's salary. A superintendent's salary is determined by various factors such as experience, level of education, age, and so on. It may also capture a superintendent's managerial quality (Meier and O'Toole 2002). Thus, the level of collaboration success may be associated with a superintendent's salary. More discussion about the association will be discussed in finding section. To correct the skewedness of the variable, this study takes a log transformation.

Lastly, a superintendent's characteristics are controlled. They include a superintendent's demographic information such as gender, race, and age.

\footnotetext{
${ }^{8}$ The correlation is .551 with a p-value of .000 .

${ }^{9}$ Controlling for total expenditure with or without expenditure in central administration does not significantly affect overall regression results.
} 


\section{Method}

The dependent variable in this study has three ordered categories (decreased, remained same, and increased) and an ordered probit regression analysis is an appropriate method to estimate such an ordinal variable (Long and Freese 2006). In order to conduct an ordered probit regression analysis, the proportional odds assumption that the relationship between all pairs of outcome groups is the same has to be satisfied. ${ }^{10}$ This assumption enables one set of coefficients for each explanatory variable to describe the odds of the dependent variable being changed from one category to another. Using STATA 12, this study conducted the approximate likelihood-ratio test of proportionality of odds across response categories, and it was found that the analyses satisfied the assumption. In order to interpret the results more easily, this study adopts the MEOPROBIT method that Cornelissen (2006) suggests. According to Cornelissen, the MEOPROBIT method re-estimates the results from ordered probit analysis in order to compute marginal probability estimates (Moynihan and Pandey 2010). As a result, interpreting estimates via the MEOPROBIT method is similar to the coefficients after ordinary least-squares analysis: a one-unit change in the explanatory variable increases a mean change on the predicted variable (Moynihan and Pandey 2010).

\section{Results}

Table 6 presents the analytic results. Model 1 estimates all 180 superintendents in the sample. Model 2 and Model 3 estimates partitioned sub-samples: the sample in Model 2 estimates 120 superintendents who had had networking with other school districts at Time 1 and the sample in Model 3 estimated 60 superintendents who had not had networking with other school districts at Time 1. In all three models, holding all other variables constant, intended-and-activated

\footnotetext{
${ }^{10}$ Introduction to STATA. UCLA: Academic Technology Services, Statistical Consulting Group. available at http://www.ats.ucla.edu/stat/stata/dae/ologit.htm (accessed August 12, 2011).
} 
networking and not-intended-but-nonetheless-activated networking brings consistently higher marginal effects as compared to intended-but-not-activated networking. ${ }^{11}$ In Model 1, superintendents of intended-and-activated networking and superintendents of not-intended-butnonetheless-activated networking results in .407 and .657 increase in the 3-point changes in the success of collaboration scale, respectively, as compared to superintendents of the intended-butnot-activated networking. Although the magnitudes of intended-and-activated networking and not-intended-but-nonetheless-activated networking are different, both variables positively influence changes in the perceived success of collaboration. Between intended-and-activated networking and not-intended-but-nonetheless-activated networking, the marginal effects for notintended-but-nonetheless-activated networking are found to be higher than the marginal effects for intended-and-activated networking across three models. Lastly, the findings reveal that notintended-and-not-activated networking is not statistically significant in all models.

These findings may imply that a manager is better off when activating networking with a candidate who takes the initiative for the networking between them. They also suggest that networking with a certain party that a manager originally intends to activate brings positive increases in the level of perceived collaboration success, but the failure of activating the intended networking can cause negative changes.

Control variables play different roles based on the sample characteristics. First, Model 1 and Model 2 show that superintendents who have a higher salary are likely to lead to a positive impact on collaboration success. Considering that a superintendent's pay is determined by various factors such as human-capital factors (level of education or length of service) or a district's characteristics (size or financial status), it is not an easy task to figure out what aspects of salary increase the success of collaboration. The findings show that salary is a significant

\footnotetext{
${ }^{11}$ Intended-but-not-activated networking is a baseline in this analysis.
} 
predictor for the success of collaboration. However, the association between salary and the success of collaboration is not statistically significant in Model 3, which samples superintendents who did not have networking with other school districts at Time 1.

Findings also reveal that white superintendents are likely to improve the perceived success of collaboration with other school districts as compared to non-white superintendents. However, it is not supported in Model 2.

A superintendent's age is another good predictor for the changes in the perceived success of collaboration with other school districts. The findings in Model 1 and Model 3 show that senior superintendents are less likely to be successful at changing the level of success of collaboration. However, it is not supported for those who had networking at Time 1.

Most control variables that are found statistically significant in Model 1 are statistically significant either in Model 2 or Model 3 as well. However, Model 2 finds that total expenditure except central administration decreases the level of perceived success of collaboration. Model 3 finds that a female superintendent is more likely to improve changes in a manager's perception on collaboration success. As for the percentage of central administrators, Model 1 finds no statistically significant impact while Model 2 finds more central administrators bring a statistically significant and positive impact on the level of perceived collaboration success with other school districts and Model 3 finds the opposite impact.

[Table 6 about here]

All these mixed results for control variables may be related to whether superintendents had networking with other school districts at Time 1. Table 7 presents an ordered probit regression analysis controlling for networking with other school districts at Time 1 . The main independent variables show similar impacts as the previous analyses: both intended-and- 
activated networking and not-intended-but-nonetheless-activated networking have positive impacts with the latter being greater. However, whether superintendents had networking with other school districts at Time 1 does not statistically influence the change of collaboration success with other school districts. Meanwhile, results show that statistical powers of all control variables are similar to those in Model 1 in Table 6.

[Table 7 about here]

These findings suggest that control variables are systematically different between two sup-samples, but the independent variables of interest are robust and not affected by whether superintendents had had networking with other school districts at Time 1.

In summary, the findings above suggest that intended-and-activated networking and notintended-but-nonetheless-activated networking have a positive impact on the level of perceived success of collaboration. Furthermore, marginal effects of not-intended-but-nonethelessactivated networking are greater than those of intended-and-activated networking. It may suggest that the best strategy for managers when selecting partners is to wait until the other partner comes to the managers for networking. However, is it really so? Although managers of notintended-but-nonetheless-activated networking are better off, if the possibility of such occurrence is rare, it may not be an optimal case for managers. In fact, the sample of this study shows that the actual number of superintendents that held the not-intended-but-nonethelessactivated networking is few. As shown in Table 4, out of 180 superintendents in the sample, only 12 superintendents (6.7 percent) held the not-intended-but-nonetheless-activated networking. About 33 percent of superintendents $(n=59)$ in the sample had the intended-and-activated networking. This result suggests that the strategy of the not-intended-but-nonetheless-activated 
networking may bring the highest utility but it is unlikely; thus, it is not a good strategy for managers.

Table 8 computes and compares expected values between intended-and-activated networking and not-intended-but-nonetheless-activated networking. Expected value refers to "the weighted average of their outcomes" (Kahneman, 2003, p. 703) and it is derived by multiplying its utility and the probability of its occurring. According to Kaya and Kahraman (2011), the principle of expected utility maximization states that among a set of competing alternative choices, a rational decision maker chooses a decision which will maximize his/her expected utility. The expected values in Table 8 are outcomes of marginal effects multiplied by the number of each case out of the sample. Considering the definition of the expected values, the values in Table 8 are not exact expected values per se. Although the marginal effects represents the utility for each networking case, the probabilities of each scenario are not completely random; rather, it represents how superintendents in the sample already behaved at the particular period that surveys were conducted. Thus, the result in Table 7 may not be generalizable. However, the findings may help to assess superintendents in the sample in terms of their decision-making. Based on the result, this study may draw an implication about how managers make decisions when they select networking partners.

[Table 8 about here]

The comparison of expected values for intended-and-activated networking and for notintended-but-nonetheless-activated networking in Table 8 shows different stories compared to the regression results in Table 6 and Table 7. The regression results show that not-intended-butnonetheless-activated networking brings higher marginal effects on the change of the perceived success of collaboration than intended-and-activated networking. However, as shown in Table 8, 
the expected value for intended-and-activated networking $(=.133)$ is higher than the expected value for not-intended-but-nonetheless-activated networking $(=.044)$. In other words, as compared to the effect size of not-intended-but-nonetheless-activated networking, intended-andactivated networking has lower positive impacts on the perceived change in the level of collaboration success. However, considering the likelihood of each networking scenario, it is a better strategy for managers to actively search for a networking partner and activate networking with that partner.

\section{Conclusion and Discussion}

The recent interest in networks has developed an understanding of the various aspects of networks. Despite the active research on networks, few studies have explored the issue of networking partner selection even if the significance of this topic has been discussed (Agrnoff and McGurie 2001; Jarimo et al., 2006; Robinson and Bies 2010). To fill this gap, four possible scenarios of networking partner selection are suggested in this study. Based on cost-benefit assessment concept, this study finds that not-intended-but-nonetheless-activated networking results in the highest positive impacts on changes in the success level of collaboration, while intended-and-activated networking is the second highest. However, the scenario of not-intendedbut-nonetheless-activated networking is unlikely and the expected value of intended-andactivated networking and not-intended-but-nonetheless-activated networking in the sample show that the former has a higher expected value than the latter. This result suggests that managers would be better off when they actively search the potential networking partners and to get their networking activated.

Although this study is one of the first studies that investigate decision making in networking partner selection and its impact on the level of perceived success of collaboration, 
future research is expected to deal with some limitations that this study has, particularly the perception measure of the success of collaboration. This study relies on a measure that depends on one's perception because there is no archival way to objectively measure the success of collaboration. However, this may not be an ideal measure and future research is expected to develop more objective measure of collaboration success.

In addition, as stated earlier, this study could investigate partner selection and its impact in the change of success of collaboration with 1) police, fire department, and first responders, 2) government relief and welfare organizations, 3) nonprofit and relief organizations, 4) local/community/religious organizations, 5) other school districts, and 6) business organizations. If theories hold, the hypotheses that this study proposes could have been tested for all six external organizations. However, only the model investigating the change of success of collaboration with other school districts has statistically significant goodness-of-fit. In other words, given independent variables of interest and control variables are jointly insignificant for the other five models. Different characteristics of external organizations may cause such differences. However, with the given data, it is not certain. In order to ensure external validity, future research in different policy contexts should follow.

Lastly, five assumptions are set to describe each scenario. However, this study admits that each assumption may not hold in the real world. As a result, each decision-making in the real world may not just be the way this study describes. Therefore, arguments and findings from this study require careful applications to management in the real world. To test the external validity, future research is necessary to test each assumption if possible or develops the process of networking partner selection suggested in this study. 
In conclusion, with admission of these limitations, this study is still valuable in that it takes the first step to understand the process of networking partner selection, and future research with more refined theoretical frameworks, variables, and methodology is expected. 
Table 1. Scenarios of Networking Partner Selection

\begin{tabular}{|l|c|c|c|}
\hline \multirow{2}{*}{\multicolumn{2}{|c|}{}} & \multicolumn{2}{|c|}{ Networking Intended at Time T } \\
\cline { 3 - 4 } & & Yes & No \\
\hline \multirow{2}{*}{$\begin{array}{c}\text { Networking } \\
\text { Activated at Time T+1 }\end{array}$} & Yes & Scenario I & Scenario II \\
\cline { 2 - 4 } & & & \\
& No & Scenario III & Scenario IV \\
\hline
\end{tabular}


Table 2. Costs and Benefits in the Scenarios of Networking Partner Selection

\begin{tabular}{|c|c|c|c|c|c|}
\hline & & \multicolumn{4}{|c|}{ Networking Intended at Time $\mathrm{T}$} \\
\hline & & \multicolumn{2}{|l|}{ Yes } & \multicolumn{2}{|c|}{ No } \\
\hline \multirow{4}{*}{$\begin{array}{c}\text { Networking } \\
\text { Activated at } \\
\text { Time } \mathrm{T}+1\end{array}$} & & Cost & Benefits & Cost & Benefits \\
\hline & Yes & $\begin{array}{l}\text { 1) Self-evaluation } \\
\text { 2) The attempt to activate } \\
\text { collaboration } \\
\text { 3) The process of } \\
\text { activation }\end{array}$ & $\begin{array}{c}\text { Success of } \\
\text { Collaboration }\end{array}$ & $\begin{array}{l}\text { 1) Self-evaluation } \\
\text { 2) The process of } \\
\text { activation }\end{array}$ & $\begin{array}{c}\text { Success of } \\
\text { Collaboration }\end{array}$ \\
\hline & & Cost & Benefits & Cost & Benefits \\
\hline & No & $\begin{array}{l}\text { 1) Self-evaluation } \\
\text { 2) The attempt to activate } \\
\text { collaboration }\end{array}$ & $\mathrm{N} / \mathrm{A}$ & 1) Self-evaluation & $\mathrm{N} / \mathrm{A}$ \\
\hline
\end{tabular}


Table 3. Distribution of Collaboration Success Changes

Dependent Variable: Change in Collaboration Success Freq. Percent Cum.

\begin{tabular}{cccc}
\hline-3 & 2 & 1.11 & 1.11 \\
-2 & 5 & 2.78 & 3.89 \\
-1 & 52 & 28.89 & 32.78 \\
0 & 87 & 48.33 & 81.11 \\
1 & 28 & 15.56 & 96.67 \\
2 & 6 & 3.33 & 100.00 \\
\hline Total & 180 & 100 &
\end{tabular}


Table 4. Transformed Collaboration Success Changes

Dependent Variable: Change in Collaboration Success Freq. Percent Cum.

\begin{tabular}{cccc}
\hline Decrease & 59 & 28.89 & 32.78 \\
Remain Same & 87 & 48.33 & 81.11 \\
Increase & 34 & 18.89 & 100 \\
\hline Total & 180 & 100.00 &
\end{tabular}


Table 5. Counts of Partner Selection Scenarios

\begin{tabular}{|c|c|c|c|c|}
\hline & & \multicolumn{2}{|c|}{$\begin{array}{c}\text { Intended on Sustaining Regular } \\
\text { Contact with Other School Districts } \\
\text { ('05-'06) }\end{array}$} & \\
\hline & & Yes & No & Sum \\
\hline $\begin{array}{c}\text { Holding Regular Meeting } \\
\text { with Other School Districts } \\
\text { ('07) }\end{array}$ & Yes & 59 & 12 & 71 \\
\cline { 2 - 5 } & No & 90 & 19 & 109 \\
\hline & Sum & 149 & 31 & 180 \\
\hline
\end{tabular}


Table 6. Ordered Probit Regression of Changes in the Success of Collaboration with Other School Districts

\begin{tabular}{|c|c|c|c|c|c|c|}
\hline \multirow{2}{*}{$\begin{array}{l}\text { Dependent Variable: Changes of the Success of } \\
\text { Collaboration w/ Other School Districts } \\
\text { VARIABLES }\end{array}$} & \multicolumn{2}{|c|}{$\begin{array}{c}\text { Model } 1 \\
\text { (Whole Sample) }\end{array}$} & \multicolumn{2}{|c|}{$\begin{array}{c}\text { Model } 2 \\
\left(\text { Sub-Sample } 1^{+}\right)\end{array}$} & \multicolumn{2}{|c|}{$\begin{array}{c}\text { Model 3 } \\
\left(\text { Sub-Sample 2 } 2^{++}\right)\end{array}$} \\
\hline & $\begin{array}{c}\text { Raw } \\
\text { Coefficient }\end{array}$ & $\begin{array}{l}\text { Marginal } \\
\text { Effects }\end{array}$ & $\begin{array}{c}\text { Raw } \\
\text { Coefficient }\end{array}$ & $\begin{array}{l}\text { Marginal } \\
\text { Effects }\end{array}$ & $\begin{array}{c}\text { Raw } \\
\text { Coefficient }\end{array}$ & $\begin{array}{c}\text { Marginal } \\
\text { Effects }\end{array}$ \\
\hline $\begin{array}{l}\text { Intended-and-Activated Networking w/ Other } \\
\text { School Districts }\end{array}$ & $\begin{array}{l}0.677 * * * \\
(0.200)\end{array}$ & 0.407 & $\begin{array}{c}0.623 * * * \\
(0.234)\end{array}$ & 0.375 & $\begin{array}{c}1.600 * * * \\
(0.533)\end{array}$ & 0.752 \\
\hline $\begin{array}{l}\text { Not-intended-but-Nonetheless-Activated } \\
\text { Networking w/ Other School Districts }\end{array}$ & $\begin{array}{c}1.121^{* * *} \\
(0.401)\end{array}$ & 0.657 & $\begin{array}{l}0.982 * \\
(0.511)\end{array}$ & 0.587 & $\begin{array}{c}2.056^{* * *} \\
(0.790)\end{array}$ & 0.930 \\
\hline $\begin{array}{l}\text { Not-intended-and-Not-activated Networking w/ } \\
\text { Other School Districts }\end{array}$ & $\begin{array}{c}0.421 \\
(0.294)\end{array}$ & 0.255 & $\begin{array}{c}0.063 \\
(0.452)\end{array}$ & 0.038 & $\begin{array}{c}0.372 \\
(0.454)\end{array}$ & 0.176 \\
\hline Recent Emergency Plan Activation & $\begin{array}{l}-0.020 \\
(0.091)\end{array}$ & -0.012 & $\begin{array}{l}-0.170 \\
(0.111)\end{array}$ & -0.103 & $\begin{array}{c}0.305 \\
(0.198)\end{array}$ & 0.144 \\
\hline$\%$ Central Administration & $\begin{array}{c}0.134 \\
(0.142)\end{array}$ & 0.080 & $\begin{array}{l}0.351^{*} \\
(0.179)\end{array}$ & 0.212 & $\begin{array}{l}-0.528^{*} \\
(0.309)\end{array}$ & -0.250 \\
\hline $\begin{array}{l}\text { Total Expenditure per Pupil } \\
\text { (logged; except central administration) }\end{array}$ & $\begin{array}{l}-0.228 \\
(0.405)\end{array}$ & -0.137 & $\begin{array}{c}-1.126^{* *} \\
(0.571)\end{array}$ & -0.679 & $\begin{array}{l}-0.103 \\
(0.802)\end{array}$ & -0.049 \\
\hline Superintendent's Salary (logged) & $\begin{array}{c}0.669^{* *} \\
(0.289)\end{array}$ & 0.402 & $\begin{array}{c}1.384 * * * \\
(0.418)\end{array}$ & 0.835 & $\begin{array}{l}-0.323 \\
(0.477)\end{array}$ & -0.153 \\
\hline Female Superintendent & $\begin{array}{c}0.209 \\
(0.227)\end{array}$ & 0.127 & $\begin{array}{l}-0.093 \\
(0.291)\end{array}$ & -0.056 & $\begin{array}{c}0.979 * * \\
(0.462)\end{array}$ & 0.464 \\
\hline White Superintendent & $\begin{array}{l}0.602 * \\
(0.326)\end{array}$ & 0.344 & $\begin{array}{c}0.540 \\
(0.426)\end{array}$ & 0.311 & $\begin{array}{l}1.176^{*} \\
(0.623)\end{array}$ & 0.538 \\
\hline Superintendent's Age & $\begin{array}{c}-0.030 * * \\
(0.013)\end{array}$ & -0.018 & $\begin{array}{l}-0.019 \\
(0.016)\end{array}$ & -0.011 & $\begin{array}{c}-0.080^{* * *} \\
(0.028)\end{array}$ & -0.038 \\
\hline Constant & $\begin{array}{c}4.575 \\
(4.788)\end{array}$ & & $\begin{array}{l}5.175 \\
(6.257)\end{array}$ & & $\begin{array}{l}-8.008 \\
(9.190)\end{array}$ & \\
\hline Constant & $\begin{array}{c}6.042 \\
(4.797)\end{array}$ & & $\begin{array}{r}6.625 \\
(6.266) \\
\end{array}$ & & $\begin{array}{l}-5.966 \\
(9.156)\end{array}$ & \\
\hline $\begin{array}{l}\text { Observations } \\
\text { Pseudo R-squared }\end{array}$ & $\begin{array}{r}18 \\
0.0\end{array}$ & & & & $\begin{array}{r}0 \\
0.2 \\
\end{array}$ & \\
\hline
\end{tabular}

+Sample of superintendents who had had networking with other school districts at Time 1

++ Sample of superintendents who had not had networking with other school districts at Time 1

Standard errors in parentheses

$* * * \mathrm{p}<0.01, * * \mathrm{p}<0.05, * \mathrm{p}<0.1$ 
Table 7. Ordered Probit Regression of Changes in the Success of Collaboration with Other School Districts

\begin{tabular}{|c|c|c|}
\hline VARIABLES & $\begin{array}{c}\text { Raw } \\
\text { Coefficient }\end{array}$ & $\begin{array}{l}\text { Marginal } \\
\text { Effects }\end{array}$ \\
\hline Intended-and-Activated Networking w/ Other School Districts & $\begin{array}{c}0.744 * * * \\
(0.207)\end{array}$ & 0.446 \\
\hline $\begin{array}{l}\text { Not-intended-but-Nonetheless-Activated Networking w/ Other School } \\
\text { Districts }\end{array}$ & $\begin{array}{c}1.115^{* * * *} \\
(0.401)\end{array}$ & 0.652 \\
\hline Not-intended-and-Not-activated Networking w/ Other School Districts & $\begin{array}{c}0.382 \\
(0.295)\end{array}$ & 0.231 \\
\hline Holding Networking w/ Other School Districts at Time 1 & $\begin{array}{l}-0.281 \\
(0.201)\end{array}$ & -0.169 \\
\hline Recent Emergency Plan Activation & $\begin{array}{l}-0.025 \\
(0.092)\end{array}$ & -0.015 \\
\hline$\%$ Central Administration & $\begin{array}{c}0.151 \\
(0.143)\end{array}$ & 0.090 \\
\hline Total Expenditure per Pupil (logged; except central administration) & $\begin{array}{l}-0.395 \\
(0.424)\end{array}$ & -0.237 \\
\hline Superintendent's Salary (logged) & $\begin{array}{c}0.736 * * \\
(0.293)\end{array}$ & 0.442 \\
\hline Female Superintendent & $\begin{array}{c}0.206 \\
(0.228)\end{array}$ & 0.124 \\
\hline White Superintendent & $\begin{array}{l}0.636^{*} \\
(0.328)\end{array}$ & 0.361 \\
\hline Superintendent's Age & $\begin{array}{c}-0.029 * * \\
(0.013)\end{array}$ & -0.017 \\
\hline Constant & $\begin{array}{c}3.749 \\
(4.825)\end{array}$ & \\
\hline Constant & $\begin{array}{r}5.225 \\
(4.832) \\
\end{array}$ & \\
\hline $\begin{array}{l}\text { Observations } \\
\text { Pseudo R-squared }\end{array}$ & \multicolumn{2}{|c|}{$\begin{array}{c}180 \\
0.081\end{array}$} \\
\hline
\end{tabular}

Standard errors in parentheses

$* * * \mathrm{p}<0.01, * * \mathrm{p}<0.05, * \mathrm{p}<0.1$ 
Table 8. Expected Value of the Scenarios

\begin{tabular}{|c|c|c|}
\hline & $\begin{array}{c}\text { Intended-and-Activated } \\
\text { Networking }\end{array}$ & $\begin{array}{c}\text { Not-Intended-but- } \\
\text { Nonetheless-Activated } \\
\text { Networking }\end{array}$ \\
\hline $\begin{array}{c}\text { Utility } \\
\text { (Marginal Effects) }\end{array}$ & 0.407 & 0.657 \\
\hline $\begin{array}{c}\text { Probability } \\
\text { (Frequency of Each } \\
\text { Case in the Sample) }\end{array}$ & 0.328 & 0.067 \\
\hline Expected Value & 0.133 & 0.044 \\
\hline
\end{tabular}




\section{References}

Agranoff, R., \& McGuire, M. (2001). Big Questions in Public Network Management Research. Journal of Public Administration Research and Theory, 11(3), 295-326.

Agranoff, R., \& McGuire, M. (2003). Collaborative Public Management: New Strategies for Local Governmens. Washington, DC: Georgetown University Press.

Andrews, R., Boyne, G. A., \& Walker, R. M. (2006). Subjective and Objective Measures of Organizational Performance: An Empirical Exploration. In G. A. Boyne, K. J. Meier, L. J. O’Toole \& R. M. Walker (Eds.), Public Service Performance: Perspectives on Measurement and Management. Cambridge: Cambridge University Press.

Brewer, G. A. (2006). All Measures of Performance Are Subjective: More Evidence on US Federal Agencies. In G. A. Boyne, K. J. Meier, L. J. O'Toole \& R. M. Walker (Eds.), Public Service Performance: Perspectives on Measurement and Management. Cambridge: Cambridge Unviersity Press.

Cornelissen, T. (2006). MEOPROBIT: Stata module to computemarginal effects after estimation of ordered probit. Retrieved Feburuary 02, 2012, from http://ideas.repec.org/c/boc/bocode/s456788.html

Fleishman, R. (2009). To Participate or Not to Participate? Incentives and Obstacles for Collaboration. In R. O'Leary \& L. B. Bingham (Eds.), The Collaborative Public Manager: New Ideas for the Twentyfirst Century (pp. 31-52). Washington D.C.: Georgetown University Press.

Frederickson, H. G. (1999). The Repositioning of American Public Administration. PS: Political Science and Politics, 32(4), 701-711.

Graddy, E. A., \& Chen, B. (2009). Partner Selection and the Effectiveness of Interorganizational Collaborations. In R. O'Leary \& L. Bingham (Eds.), The collaborative public manager: new ideas for the twenty-first century (pp. 53-69). Washington, DC.: Georgetown University Press.

Hall, T. E., \& O'Toole, L. J., Jr. (2000). Structures for Policy Implementation: An Analysis of National Legislation, 1965-1966 and 1993-1994. Administration Society, 31(6), 667-686.

Hicklin, A., O'Toole, L. J., Jr., \& Meier, K. J. (2008). Serpents in the Sand: Managerial Networking and Nonlinear Influences on Organizational Performance. Journal of Public Administration Research and Theory, 18(2), 253-273.

Jarimo, T., Salkari, I., \& Bollhalter, S. (2006). Partner Selection With Network Interdependencies: An Application Network-Centric Collaboration and Supporting Frameworks (Vol. 224, pp. 389-396): Springer Boston.

Kahneman, D. (2003). A perspective on judgment and choice: Mapping bounded rationality. American Psychologist, 58(9), 697-720.

Kaya, İ., \& Kahraman, C. (2011). Evaluation of Green and Renewable Energy System Alternatives Using a Multiple Attribute Utility Model: The Case of Turkey Soft Computing in Green and Renewable Energy Systems. In K. Gopalakrishnan, S. Khaitan \& S. Kalogirou (Eds.), (Vol. 269, pp. 157182): Springer Berlin / Heidelberg.

Long, J. S., \& Freese, J. (2006). Regression Model for Categorical Dependent Variables Using Stata (2nd ed.). College Station, Texas: Stata.

Meier, K. J., \& O'Toole, L. J. (2002). Public Managemetn and Organizational Performance: The Impact of Manaterial Quality. journal of Policy Analysis and Management, 21(3), 629-643.

Meier, K. J., \& O'Toole, L. J. (2010). I Think (I am doing well), Therefore I Am: Assessing the Validity of Administrators' Self-assessments of Performance. Paper presented at the the annual meetings of the Midwest Political Science Association.

Meier, K. J., O'Toole, L. J., \& Hicklin, A. (2010). I've Seen Fire and I've Seen Rain: Public Management and Performance After a Natural Disaster. Administration \& Society, 41(8), 979-1003.

Moynihan, D. P., \& Pandey, S. K. (2010). The Big Question for Performance Management: Why Do Managers Use Performance Information? Journal of Public Administration Research and Theory, 20(4), 849-866.

Nas, T. (1996). Cost-Benefit Analysis: Theory and application. London: SAGE.

O'Toole, L. J. (1997). Treating Networks Seriously: Practical and Research-Based Agendas in Public Administration. Public Administration Review, 57(1), 45-52.

Oliver, A. L., \& Ebers, M. (1998). Networking Network Studies: An Analysis of Conceptual Configurations in the Study of Inter-organizational Relationships. Organization Studies, 19(4), 549-583. 
Provan, K. G., Fish, A., \& Sydow, J. (2007). Interorganizational Networks at the Network Level: A Review of the Empirical Literature on Whole Networks. Journal of Management, 33(3), 479-516.

Robinson, S. E. (2011). School District Partner Choice in Emergency Management Collaboration. Risk, Hazards \& Crisis in Public Policy, 2(2), 1-17.

Robinson, S. E., \& Bies, A. (2010). Structured to Partner: School District Collaboration with Nonprofit Organizations in Disaster Response. Bush School Working Paper \# 615.

Robinson, S. E., \& Gettis, B. S. (2007). Seeing Past Parallel Play: Survey Measures of Collaboration in Disaster Situations.

Scharpf, F. (1978). Interorganizational Policy Studies: Issues, Concepts and Perspectives. In K. H. a. F. W. Scharpf (Ed.), Interorganizational Policy Making (pp. 345-370). London: Sage Publications.

Selden, S. C., Sowa, J. E., \& Sandfort, J. (2006). The Impact of Nonprofit Collaboration in Early Child Care and Education on Management and Program Outcomes. Public Administration Review, 66(3), 412-425.

Van de Ven, A., Emmett, D., \& Koenig Jr., R. (1975). Frameworks for Interorganizational Analysis. In A. Negandhi (Ed.), Interorganizational Theory. Kent, OH: Kent State University Press. 